\title{
THE TEACHING AND INTEGRATION OF PSYCHOLOGY INTO SAUDI ARABIAN CURRICULUM
}

\author{
Kyle A Msall \\ PhD' King Fahd Security College (Saudi Arabia)
}

\begin{abstract}
The current state of psychology is examined in Saudi Arabia which includes stigma, professional outlook, and underserved populations. These have an effect on instructors and professors that are teaching psychology within the region and/or to this population. Teaching psychology in the Gulf Cooperation Council (GCC) countries has several challenges that one must take into consideration while developing and delivering the course. In Saudi Arabia, there are several aspects of psychology that can be incorporated and must be dismissed due to the conservative Islamic society. Psychology courses must be adapted to the cultural context. Courses that are well adapted to the cultural context in undergraduate education throughout the Middle East have the possibility to bring about acceptance of psychology and reduce stigma overall. At some universities in Saudi Arabia, the integration of psychology into the curriculum is meant to support specific programs such as criminal justice. Not only does it support criminal justice, but students are learning basic and more advanced psychological concepts through different means than most university settings. This forces psychology to become a more interdisciplinary field at an earlier stage of learning. A review of the literature on integrating non-western cultures into psychology courses is discussed to incorporate psychology into other programs.
\end{abstract}

Keywords: Teaching psychology, Middle East, interdisciplinary psychology, non-western cultures.

\section{Introduction}

The Kingdom of Saudi Arabia is the largest country in the Gulf Cooperation Council (referred to as GCC henceforth). It includes the two holy sites of Islam and is therefore subject to strict Sharia law that all citizens, residents, and visitors must abide by. Although Saudi Arabia has been viewed as very strict in this regard in the past, there is a sense of change toward a more progressive society, albeit slowly. In the past year, females have begun to drive, different economic policies have been promoted, and several major sporting and music events have taken place in the Kingdom for the first time ever. This is great for the people living there but it also has an impact on education within Saudi Arabia.

Public education in Saudi Arabia in the past has lacked the necessary resources to become a serious contender on the world education stage. However, since 1992, the literacy rate among adults in Saudi Arabia has increased from $70 \%$ to $95 \%$ (Knoema). Although literacy rates have increased, the overall effectiveness of the education system and the students' ability to apply what they have learned has been in question for quite some time. The notion of Academic Entitlement is usually placed upon Western students and suggests that these students believe they are entitled to an education and is often associated with problematic behaviors and attitudes, which could include incivility in the classroom and the endorsement and normalcy of cheating among students (Blincoe and Garris, 2017). However, the study conducted by Blinco and Garris (2017) revealed that the rates of Academic Entitlement were much higher in Saudi Arabia when compared to rates among the US. This Academic Entitlement, it seems, is a major interruption within the classroom and can be noticed throughout the semester by the students.

Currently in the GCC, there are minimal laws and regulations for practicing psychologists or therapists. It is very easy for someone to claim they are a psychologist and provide "therapy" for individuals which could lead to more harm than good. As with other regions in the world, stigma is a major issue throughout the Middle East (McCrae, Shari, and Norman, 2019). It is often thought of as demeaning to go to therapy or the individual is automatically labelled as "crazy" which is similar to stigma across the world. However, a unique aspect of the Middle East, and especially Saudi Arabia, is the family name and tribe (AlAteeq, et al., 2018). The gravity that the family name plays in the future of the 
individual, and even the extended family, is immense. For this reason, many individuals do not seek out mental health services resulting in many mental health issues left untreated.

The high rates of Academic Entitlement and the stigma of psychology do become issues when teaching psychology within Saudi Arabia and one must integrate many different aspects in to the psychology curriculum in order to satisfy the cultural norms. Psychology as a field was founded by western philosophers and academics and has developed over time within these western contexts. It is often exported around the globe without any additional cultural relevance research or cultural modification done to the curriculum. If this is not enough, many non-western clinicians are trained in western countries and then go back to their home countries to practice western psychology within non-western contexts (Badri, 2016). This not only shows the ethnocentrism of the west but could lead to difficulties in therapy and cultural faux paus in the classroom. This is especially the case in Saudi Arabia where Sharia law rules. The current paper examines literature that offer ways for psychology instructors to modify their courses to a more culturally relevant course. This could do two things for the field of psychology: the first being, reducing stigma in societies that have historically not been able to openly address mental health issues; the second being, to spread psychology to non-western cultures in order to make the field more culturally relevant for specific cultural contexts.

\section{Method}

The current study's aim is to identify relevant strategies for modifying psychology courses to fit non-western cultures and in this particular study, the Islamic culture within Saudi Arabia. A literature review was carried out with the criteria of the literature set at adopting western psychology to non-western cultures. There is a limited amount of research published on this subject related to Islamic societies so best practices from other cultures were also sought after. The articles had to be peer-reviewed and published on or after 2015 until present to make sure the articles were appropriate and relatable.

\section{Results and discussion}

Although there are official divisions within the American Psychological Association focusing on cultural, international, and teaching psychology, the number of articles published since 2015 which related to modifying psychology courses to non-western courses was minimal. Of the nine published articles that were read focusing on this subject, only two were directly related to modifying a psychology course to an Islamic culture. This is an interesting find since there seems to be a consensus in the literature that psychology has failed to incorporate minority and diverse populations' experiences and worldviews into the curriculum (Chitindingu \& Mkhize, 2016; Long, 2013; Blokland-Eskell, 2005; Pillay \& Kramers, 2003). In fact, Chitindingu and Mkhize (2016) found that none of their participants reported that any of the curriculum had any coverage of indigenous knowledge systems of their particular African culture. An additional find was that psychology courses were tailored to the English language which non-English language natives found difficult to understand some of the psychological concepts. Although it may not be possible for instructors to translate some of these concepts to the language and culture they are teaching in, there is the possibility that instructors could use examples from the local culture to emphasis the concept.

An example of this specifically for Islam is for the instructor to make an example of Freud's Id, Ego, and Superego. The Quran describes each of these through the Islamic perspective of Nafs. The word nafs lexically refers to our soul, psyche, and heart or mind (Samah, 2018). By bringing in examples from the Quran and drawing comparisons between those examples and psychological concepts, students may be able to identity and understand these concepts better because it becomes more relevant to their own experiences and culture. With the Saudi Vision 2030, one of the goals is to improve education while ensuring that the curriculum and courses are consistent with Islamic beliefs (Mitchell \& Alfuraih, 2018). This practice of bringing in local cultural and traditional examples would support Saudi Vision 2030.

One of the major reasons instructors who teach psychology in non-western cultures have difficulty in modifying their psychological courses to a more culturally relevant course is due to the lack of research conducted with non-western populations. According to Rad, Martingano, and Ginges (2018), not a single study in the issues of Psychological Science in 2017 included samples of Africa or the Middle East while over $70 \%$ of the studies included samples from western countries in North American, western Europe, and Australia. While this may be due to the resources available for psychological research within these countries, the researchers and academics that carry out studies could include non-western samples as well. It seems that although it is agreed that psychology has a diversity problem, no action has been taken to improve this issue. Research that includes different cultures, ethnicities, and religions is essential 
to the development of a more inclusive psychology and the development of more culturally relevant psychology courses for non-western cultures.

A recommendation for the universities and instructors in non-western countries for teaching psychology is to include psychology in curriculum of other majors. An example of this is having psychology in a criminology program at a college in Riyadh. Although the course is entitled introduction to psychology, the content can be modified not only toward being more culturally relevant but also to include aspects of psychology that is pertinent to the students' major. The course may not be a traditional introduction to psychology course but would fit the program better. One aspect that could be focused on more in this course could be the subject of memory in which you could include eye witness testimony. This would enforce the need of psychology for the program and give a reason for the students to study this particular subject. Including these courses in other programs in non-western colleges and universities could also introduce mental health into a society where mental health is not confronted or a society where stigma is prominent.

\section{References}

AlAteeq, D., AlDaoud, A., AlHadi, A., AlKhalaf, H., \& Milev, R. (2018). The experience and impact of stigma in Saudi people with a mood disorder. Annals of general psychiatry, 17(1), 51.

Badri, M. (2016). Cultural and Islamic adaptation of psychology: A book of collected papers (Vol. 1). Human Behaviour Academy.

Blincoe, S., \& Garris, C. P. (2017). Challenging the assumption of a Western phenomenon: Academic entitlement in Saudi Arabia. The Journal of Experimental Education, 85(2), 278-290.

Blokland-Eskell, L.M. 2005. Voice to the Silent: An Ecology of Local Knowledge in Psychology. Unpublished Doctoral Thesis. Pretoria, South Africa: University of Pretoria.

Chitindingu, E., \& Mkhize, N. (2016). Listening to black African psychologists' experiences of social and academic inclusion: Incorporating indigenous knowledge systems into the curriculum. Alternation Special Edition, 18, 72-98.

Long, W. 2013. 'Market Relevance', 'Social Relevance', and Psychology in South Africa. South African Journal of Psychology 43, 4: 434-444.

Mitchell, B., \& Alfuraih, A. (2018). The Kingdom of Saudi Arabia: Achieving the Aspirations of the National Transformation Program 2020 and Saudi Vision 2030 Through Education. Journal of Education and Development, 2(3), 36.

McCrae, N., Sharif, L., \& Norman, I. (2019). Media portrayals of mental disorder in Saudi Arabia: a review of popular newspapers. Transcultural Psychiatry, 1363461518819117.

Pillay A.L. \& A.L. Kramers 2003. South African Clinical Psychology, Employment (In)Equity and the Brain Drain. South African Journal of Psychology 33,1: 52-60.

Rad, M. S., Martingano, A. J., \& Ginges, J. (2018). Toward a psychology of Homo sapiens: Making psychological science more representative of the human population. Proceedings of the National Academy of Sciences, 115(45), 11401-11405.

Samah, F. (2018, June). The Qur'an and mental health. In The Psychologist.

Saudi Arabia - Adult literacy rate. (n.d.). In Knoema. 